\title{
Treadmill exercise influences the microRNA profiles in the bone tissues of mice
}

\author{
HUAN YANG $^{1 *}$, ZHEN CAO $^{1 *}$, YANG WANG $^{1,2}$, JIAHUI WANG $^{1}$, JINTAO GAO $^{1}$, \\ BIAO HAN ${ }^{1}$, FANGMEI YU ${ }^{1}$, YIXIONG QIN $^{1}$ and YONG GUO ${ }^{1}$ \\ ${ }^{1}$ Department of Biomedical Engineering, College of Biotechnology, Guilin Medical University, \\ Guilin, Guangxi 541004; ${ }^{2}$ Department of Biomedical Engineering, Bioengineering \\ College of Chongqing University, Chongqing 400044, P.R. China
}

Received November 4, 2020; Accepted May 28, 2021

DOI: $10.3892 / \mathrm{etm} .2021 .10467$

\begin{abstract}
As an important regulator involved in cell activity, microRNAs (miRNAs) are important in the process of exercise influencing bone metabolism. The present study aimed to detect and select differentially expressed miRNAs in the bone tissues of mice trained on a treadmill, predict the target genes of these differentially expressed miRNAs and lay a foundation for exploring the effect of treadmill training on bone metabolism through miRNAs. In this experiment, after the mice were trained on a treadmill for 8 weeks, the mechanical properties of mouse femur bone were assessed, and the alkaline phosphatase (ALP) activity and osteocalcin $(\mathrm{OCN})$ protein levels of the bone were assayed. miRNA microarray and reverse transcription-quantitative (RT-q)PCR were performed to select and validate differentially expressed miRNAs in the bone, and the target genes of these miRNAs were predicted with bioinformatics methods. In addition, the differentially expressed miRNAs in the bone tissues were compared with those in mechanically strained osteocytes in vitro. Treadmill training improved the mechanical properties of the femur bones of mice, and elevated the ALP activity and OCN protein level in the bone. In addition, 122 differentially expressed miRNAs were detected in the bone, of which nine were validated via RT-qPCR. Among the target genes of these differentially expressed miRNAs, certain candidates were involved in bone metabolism. A total of eight miRNAs were differentially expressed in both bone tissue and osteocytes,
\end{abstract}

Correspondence to: Professor Yong Guo or Dr Jintao Gao, Department of Biomedical Engineering, College of Biotechnology, Guilin Medical University, 1 Zhiyuan Road, Lingui, Guilin, Guangxi 541004, P.R. China

E-mail: guoyong74@163.com

E-mail: jintao_gao@glmc.edu.cn

*Contributed equally

Key words: bone, microRNA, treadmill exercise, bioinformatics, osteocyte exhibiting the same expression trends, and various target genes of these eight miRNAs were also involved in bone metabolism. Treadmill training resulted in altered miRNA expression profiles in the bones of mice (mainly in osteocytes) and the differentially expressed miRNAs may serve important roles in regulating bone metabolism and osteogenic differentiation.

\section{Introduction}

Bone tissue is a typical mechanoresponsive tissue. Lack of mechanical stimulation is the major cause of the loss of bone mass and osteoporosis $(1,2)$. Exercise is able to apply mechanical stimulation to bone tissue, and the mechanical stress produced by exercise may increase the bone turnover rate and bone density (3), stimulate osteoblast activity, increase bone mass and promote bone reconstruction and metabolism $(4,5)$. Thus, exercise is one of the primary modifiable factors associated with improved bone health outcomes (6).

Certain types of exercise may result in improved bone strength, even after menopause (7). An increasing number of trials have indicated that treadmill exercise may promote bone health, particularly by suppressing estrogen deficiency-induced osteoporosis, for instance, treadmill training could increase bone mineral density in specific parts of rats, such as cortical bone (8), and treadmill exercise could increase bone density, improve the bone trabecular microstructure of mice, and inhibit osteoporosis and osteoclast activation in bone tissues of ovariectomized mice $(9,10)$. In addition, the mechanical loading of treadmill exercise substantially enhances the osteogenic response (11). However, these studies have not fully revealed the response of bone tissue to running motion stimulation at the molecular level, particularly in terms of regulation by microRNAs (miRNAs/miRs).

miRNAs, a class of small noncoding RNAs, are able to inhibit the expression of negative regulatory genes and protein-coding genes by binding to target mRNAs (12). MiRNAs participate in vital activities, including development, organ formation, tumorigenesis, cell proliferation, differentiation and apoptosis, by modulating gene expression $(12,13)$. MiRNAs have multiple roles in osteoblasts and osteoclasts in the presence of mechanical cyclical stretch (14), fluid shear stress (15), compressive force (16), orthodontic force (17) and 
microgravity (18). In addition, miRNAs regulate osteogenesis, which may be translated into novel therapeutic approaches for orthodontic conditions and bone fractures, as well as for systemic diseases, such as osteoporosis (19).

Osteocytes account for $>90 \%$ of the adult bone cell population and are critical sensors of mechanical loading in bone (20). In a previous study by our group, differentially expressed miRNAs [40 miRNAs, 10 of which were confirmed via reverse transcription-quantitative (RT-q)PCR] were identified in MLO-Y4 osteocytes mechanically stimulated in vitro (21). As osteocytes are dominant and mechanosensitive, it was speculated that the same miRNAs may be differentially expressed in mechanically stimulated osteocytes in vitro and in the bone tissue of mice subjected to exercise on a treadmill. These miRNAs are likely to be involved in the response to mechanical strain and bone metabolism.

In the present study, to explore the effect of treadmill exercise on the expression of miRNAs in the bone tissues of mice, the differentially expressed miRNAs in the bone tissues of mice trained on a treadmill were screened using a miRNA microarray and verified by RT-qPCR, and the target genes of these differentially expressed miRNAs were predicted. In addition, the differentially expressed miRNAs in mechanically stimulated osteocytes were compared with the differentially expressed miRNAs in the bone tissues of the mice. Specific differentially expressed miRNAs that exhibited the same expression trends were selected and their target genes were predicted.

\section{Materials and methods}

Treadmill running exercise. A total of 22 male BALB/c mice (age, 8 weeks old; weight, 25-30 g; purchased from Hunan Anshengmei Pharmaceutical Research Institute Co., Ltd.) were randomly divided into two groups. The treadmill training group (treadmill speed, $13 \mathrm{~m} / \mathrm{min}$; slope, $9^{\circ}$; training for $40 \mathrm{~min}$ per day at the same time each day, 6 days/week) and the control group (no treadmill training). All mice had free access to food and water under a relative humidity of $40-70 \%$, temperature of $22-25^{\circ} \mathrm{C}$ and $12-\mathrm{h}$ light/dark cycle. The training lasted for 8 weeks. All of the experimental protocols were performed according to the Guidelines for Animal Research of Guilin Medical University (Guide for the Care and Use of Laboratory Animals) and were approved by the Animal Ethics Committee of Guilin Medical University (approval no. 2019-0013; Guilin, China).

Bone tissue sampling. After 8 weeks of treadmill running exercise, the mice were all euthanized in transparent plastic boxes with $\mathrm{CO}_{2}$ at a flow rate of $20 \%$ chamber air exchange $/ \mathrm{min}$ (1.21/min) in December 2019. Death was confirmed by exposing the thorax to observe the lack of heartbeat, as well as observing pupil dilation and unresponsiveness to light. The femurs of the mice were collected and the soft tissue of the bone surface was removed. There were 11 mice in the treadmill training group and 11 rats in the control group, six of them were tested for bone mechanical properties. After testing the mechanical properties of the bone tissues of six mice, five of them were subsequently tested for alkaline phosphatase (ALP) activity and osteocalcin (OCN). The last five of the mice were used for the miRNA microarray and RT-qPCR assays. The femur bone was used for each of the assays.

Application of mechanical stimulation to osteocytes. MLO-Y4 osteocytes (purchased from Guangzhou Jennio Biotech Co., Ltd.) were seeded in $\alpha$-MEM (Invitrogen; Thermo Fisher Scientific, Inc.) containing 10\% FBS (Invitrogen; Thermo Fisher Scientific, Inc.) and 1\% penicillin (Invitrogen; Thermo Fisher Scientific, Inc.) in the loading culture chamber of a four-point bending loading device (Institute of Medical Equipment, Academy of Military Medical Sciences, Tianjin, China). The osteocytes were seeded at a density of $2.5 \times 10^{4}$ cells $/ \mathrm{cm}^{2}$ in mechanical loading plates and cultivated until they reached confluence. Cyclic mechanical tensile strain $(2,500 \mu \varepsilon, 0.5 \mathrm{~Hz}, 8 \mathrm{~h})$ was applied to the cells, the cells were cultured in serum-free medium (Invitrogen; Thermo Fisher Scientific, Inc.) during the application of mechanical load. Cells not subjected to mechanical stimulation were used as the control group. These procedures were performed according to a previously outlined method (21).

Mechanical properties of bone tissue. Using a material testing machine (RGM6010; Anhui Regal Electronic Technology Co., Ltd.), the mechanical properties of the mouse femur bones were determined in a classical three-point bending experiment with the following parameters: Preload, $0.5 \mathrm{~N}$; loading rate, $2 \mathrm{~mm} / \mathrm{min}$; and span, $10 \mathrm{~mm}$ (sufficient to break the bone tissue). The fracture (breaking) load, maximum elastic load, maximum bending stress and bending modulus of the mouse femurs were determined.

ALP and OCN measurements. The bone tissues (femurs) of the mice were weighed and fully ground with $1.5 \mathrm{ml}$ PBS in a tissue grinder, and subsequently, the grinding solution was transferred to a 2-ml Eppendorf tube and centrifuged at $4{ }^{\circ} \mathrm{C}$ and $2 \times 10^{3} \mathrm{x}$ g for $5 \mathrm{~min}$. The supernatant was then discarded, and subsequently, $0.2 \mathrm{ml}$ RIPA lysis buffer (Invitrogen; Thermo Fisher Scientific, Inc.) was added to the precipitate at the proportions of 1:10 (g:ml), and then the lysate was sonicated in an ultrasonic cell grinder $(200 \mathrm{~W}, 30$ cycles/6 sec). After centrifugation $\left(6 \times 10^{3} \mathrm{x} \mathrm{g}, 20 \mathrm{~min}, 4^{\circ} \mathrm{C}\right)$, the protein content of the supernatant was determined by a BCA protein assay kit (Beyotime Institute of Biotechnology). The ALP activity of the supernatant was detected by using an ALP kit (cat. no. A059-2-1; Nanjing Jiancheng Bioengineering Institute) according to the manufacturer's protocol. In addition, the OCN content of the bone tissue protein solution was detected using a mouse OCN ELISA kit (cat. no. H152; Nanjing Jiancheng Bioengineering Institute) according to the manufacturer's protocol.

miRNA microarray and RT-qPCR. After the bone tissues of the mice were completely shredded and ground in liquid nitrogen, the total RNA was purified by using TRIzol ${ }^{\circledR}$ RNA extraction reagent (Invitrogen; Thermo Fisher Scientific, Inc.) according to the manufacturer's protocol.

Part of the total RNA was purified with the mirVana miRNA Isolation kit (Ambion; Thermo Fisher Scientific, Inc.) and labeled with Cyanine 3 using the ULS ${ }^{\mathrm{TM}}$ mirVana miRNA ArrayLabeling kit (Ambion; Thermo Fisher Scientific, Inc.). Target labeling, hybridization, imaging and data processing 


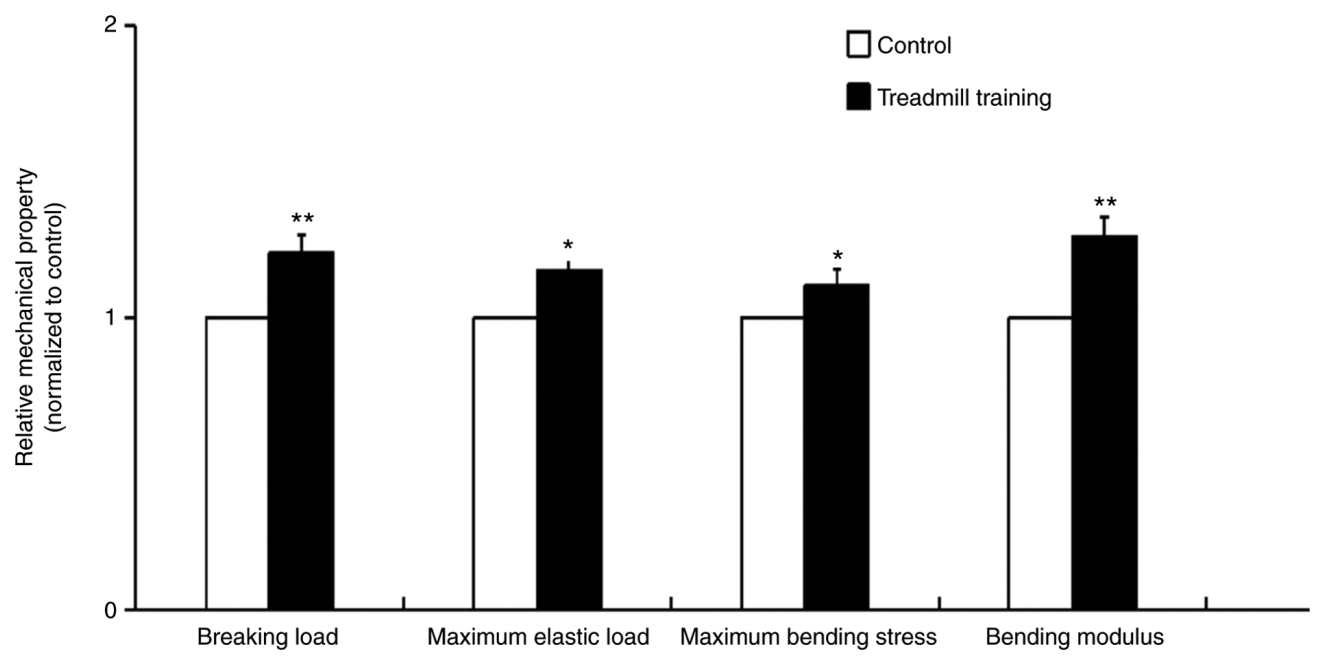

Figure 1. Mechanical properties of the femur bones in mice that were trained on a treadmill for 8 weeks. Training parameters: Speed, $13 \mathrm{~m} / \mathrm{min}$; slope, $9^{\circ}$; training for $40 \mathrm{~min} / \mathrm{day}, 6$ days/week. Treadmill training improved the mechanical properties of the femur bone. $\mathrm{n}=6$. ${ }^{*} \mathrm{P}<0.05,{ }^{* * *} \mathrm{P}<0.01 \mathrm{vs}$. Control.

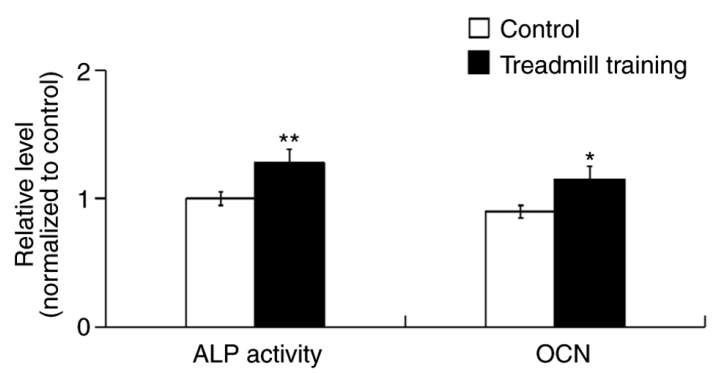

Figure 2. ALP activity and OCN content in the mouse femurs after treadmill training for 8 weeks. Treadmill training increased the ALP activity and OCN content in the femur tissues. $n=5 .{ }^{*} \mathrm{P}<0.05,{ }^{* *} \mathrm{P}<0.01$ vs. Control. ALP, alkaline phosphatase; OCN, osteocalcin.

were performed using a RiboArray miDETECT mouse array (Guangzhou RiboBio Co., Ltd.) that included all mouse miRNAs according to the manufacturer's protocol. miRNAs were considered to be differentially expressed if expression was $>2$-fold higher or lower than that in the control group $(\mathrm{P}<0.05)$.

Using the total RNA as a template, the miDETECT A Track $^{\mathrm{TM}}$ miRNA qRT-PCR Start kit (Guangzhou RiboBio Co., Ltd.) was used to perform poly(A) tailing (to tail RNA) and Uni-RT (RT based on Uni-RT primers), followed by qPCR, according to the manufacturer's protocols of the 7900HT Fast Real Time PCR machine (Applied Biosystems; Thermo Fisher Scientific, Inc.). The miRNA-specific primers miDETECT A Track ${ }^{\mathrm{TM}}$ miRNA Forward Primers and qPCR primers for the miRNA mature chain were synthesized by Guangzhou RiboBio Co., Ltd. Following cDNA synthesis using Megaplex ${ }^{\mathrm{TM}}$ RNA RT mix (cat. no. 4444766; Applied Biosystems; Thermo Fisher Scientific, Inc.), qPCR was performed using Power SYBR-Green PCR Master Mix (cat. no. 4367659; Applied Biosystems; Thermo Fisher Scientific, Inc.). The thermocycling conditions used were as follows: $10 \mathrm{~min}$ at $95^{\circ} \mathrm{C}$, followed by 45 cycles of $15 \mathrm{sec}$ at $95^{\circ} \mathrm{C}$ and $1 \mathrm{~min}$ at $60^{\circ} \mathrm{C}$. miRNA microarray and RT-qPCR experiments were performed at Guangzhou RiboBio Co., Ltd.

The miRNA microarray and RT-qPCR analysis of MLO-Y4 mouse osteocytes that were stimulated with a mechanical tensile strain of $2500 \mu \varepsilon$ at $0.5 \mathrm{~Hz}$ were performed as described in Zeng et al (21), this mechanical tensile strain has been demonstrated to promote the osteoblastic differentiation of osteoblasts in vitro.

miRNA target gene prediction. TargetScan (www.targetscan. org/), MicroRNA.org (www.microrna.org/) and miRDB (http://www.mirdb.org/2/) were used to predict the target genes of the miRNAs, and target genes related to osteogenic differentiation or bone metabolism were identified.

Statistical analysis. Values are expressed as the mean \pm standard deviation from three separate experiments ( $\mathrm{n}=5$ or 6 mice/group). Data were tested for normality of distribution using the Shapiro-Wilk test and differences between groups were analyzed using one-way ANOVA. Statistical analysis was performed using SPSS software (version 18; SPSS, Inc.) and $\mathrm{P}<0.05$ was considered to indicate a statistically significant difference.

\section{Results}

Evaluation of mechanical properties. After 8 weeks of treadmill training, the mechanical properties of the femur bone tissues of the mice were significantly improved. These improved properties included the breaking load, maximum elastic load, maximum bending stress and bending modulus, and the breaking load and bending modulus were particularly improved (Fig. 1). This result indicated that treadmill training was able to improve the mechanical strength and elasticity of bone tissue.

ALP activity and OCN expression. After 8 weeks of treadmill training, the ALP activity and OCN content of the femur bone tissues were significantly increased compared with in the control group (Fig. 2), which indicated that treadmill training was able to promote the osteogenic activity of cells in tissue.

Differential expression of miRNAs. After 8 weeks of treadmill training, the expression of all of the miRNAs in the femur bones was detected via miRNA microarray. A total of 


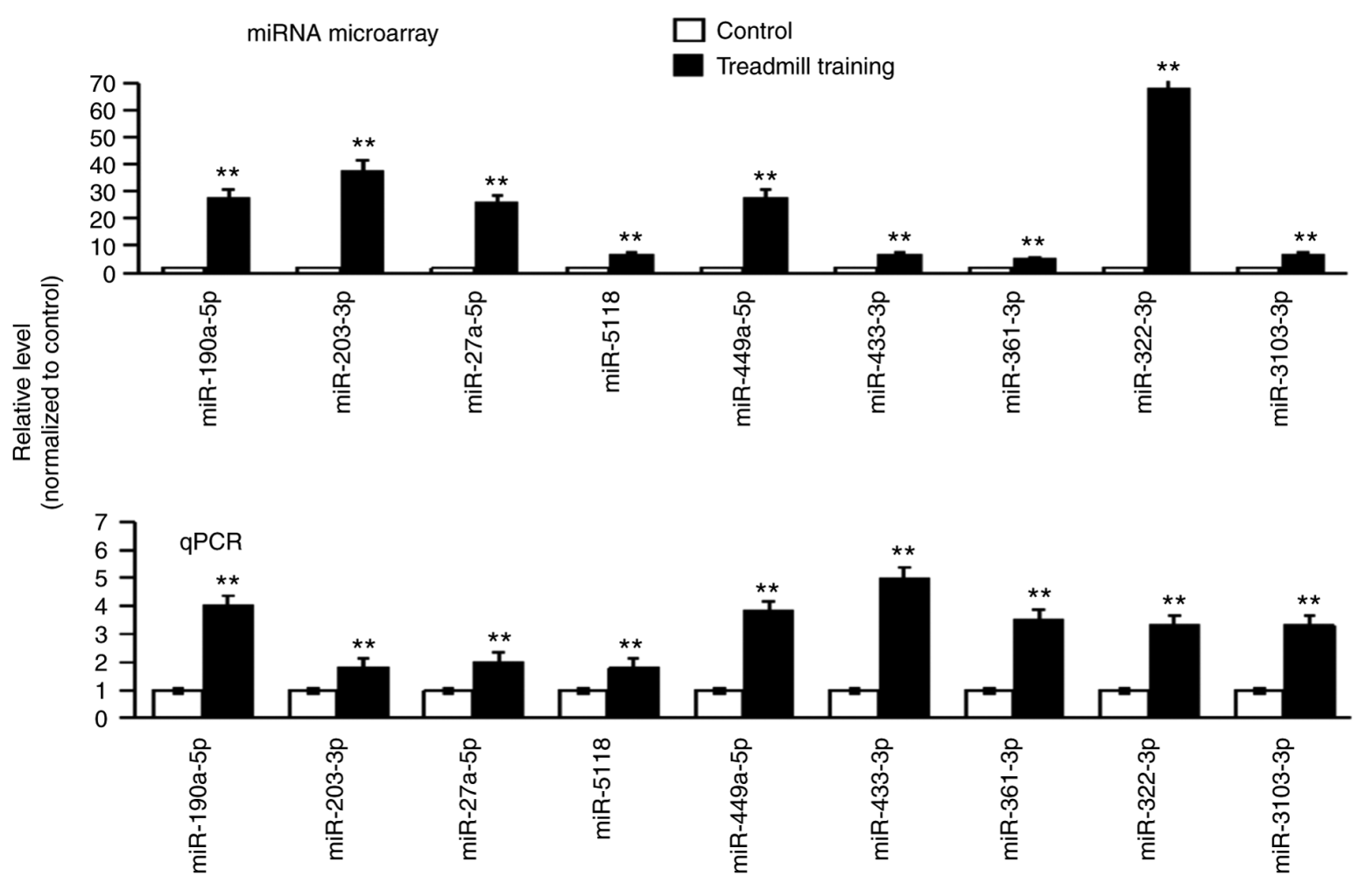

Figure 3. Microarray screening and qPCR verification of differentially expressed miRNAs in bone tissues of mice after treadmill training. The results of the chip screening are provided in the top panel and the results of $\mathrm{qPCR}$ are displayed below. $n=5$. ${ }^{* *} \mathrm{P}<0.01$ vs. Control. miR, microRNA; qPCR, quantitative PCR

122 miRNAs were indicated to be differentially expressed. From these miRNAs, 19 miRNAs with $\mathrm{P}<0.01$ were selected for further verification (data not shown). The RT-qPCR results suggested that the expression trend of each of the nine miRNAs was the same as that in the miRNA microarray; all of these miRNAs were upregulated (the expression level in the experimental group was higher compared with in the control group; Fig. 3). The nine differentially expressed miRNAs were as follows: miR-190a-5p, miR-203-5p, miR-27a-5p, miR-5118, miR-449a-5p, miR-433-3p, miR-361-3p, miR-322-3p and miR-3103-3p.

Prediction of target genes. Using bioinformatics techniques, certain osteogenic differentiation and bone metabolism-related target genes of the 9 aforementioned differentially expressed miRNAs in bone tissue were predicted and their details are presented in Table I.

Comparison of differentially expressed miRNAs. From the results of the miRNA microarray of the bone tissues and MLO-Y4 osteocytes, 19 miRNAs with the same expression trends in both bones and osteocytes were selected. These miRNAs were analyzed in bone tissues and MLO-Y4 osteocytes using RT-qPCR. The results indicated that each of the eight differentially expressed miRNAs in both the bone tissues and MLO-Y4 osteocytes had the same expression trend; four miRNAs were upregulated and four miRNAs were downregulated (Table II). The target genes of the eight differentially expressed miRNAs were predicted and Table III presents the osteogenic differentiation- and bone metabolism-related target genes, such as dickkopf homolog 2, wingless-related MMTV integration site $2 \mathrm{~b}$ (Wnt $2 \mathrm{~b}$ ), frizzled homolog 5 , transforming growth factor $\beta$ receptor, cAMP responsive element binding protein 1 .

\section{Discussion}

Bone is an important structure that bears mechanical loading and has a vital role in maintaining mineral homeostasis (22). Mechanical loading, particularly dynamic loading, is a major determinant in the regulation of the morphology and architecture of bone $(13,23)$. Suitable mechanical loading prevents bone loss or promotes bone formation, and the absence of suitable mechanical loading results in a decline in bone mass (24). Exercise produces mechanical loading, which reduces bone loss, increases bone strength and prevents osteoporosis in aging individuals $(25,26)$.

The effects of exercise on the structure and metabolism of bone tissue, such as cytokines and signaling pathways, have been studied at the cellular and molecular levels. However, only a limited number of studies have investigated the involvement of miRNAs induced by exercise in regulating bone metabolism and osteoblastic differentiation, such as mechanically-induced overexpression of miR-214 not only inhibited the expression of these osteogenic factors, but also attenuated mechanical strain-enhanced osteogenesis in osteoblasts (14).

Running is a normal form of exercise; it applies a dynamic mechanical loading to the bone tissues, particularly the femur and the tibia tissues, which is beneficial for bone health (27). In the present study, mice were forced to run on a treadmill. After 8 weeks of running exercise, it was determined that running training increased the mechanical properties of the femur, and increased the activity of 
Table I. Predictive target genes of differentially expressed miRNAs in bone tissue.

\begin{tabular}{|c|c|c|c|}
\hline miRNA & Target gene & Gene description & (Refs.) \\
\hline \multirow[t]{2}{*}{ miR-190a-5p } & Smad2 & SMAD family member 2 & $(39,47)$ \\
\hline & Cacnb2 & Calcium channel voltage-dependent $\beta 2$ subunit & $(48,49)$ \\
\hline \multirow[t]{3}{*}{ miR-203-5p } & Mmp13 & Matrix metallopeptidase 13 & $(50)$ \\
\hline & Wnt7b & Wingless-related MMTV integration site 7B & $(51)$ \\
\hline & Col3a1 & Collagen type III $\alpha 1$ & $(52,53)$ \\
\hline \multirow[t]{3}{*}{ miR-27a-5p } & Ngfr & Nerve growth factor receptor & $(54)$ \\
\hline & Stk38 & Serine/threonine kinase 38 & $(55)$ \\
\hline & Ube $2 \mathrm{~d} 2 \mathrm{a}$ & Ubiquitin-conjugating enzyme E2D 2A & $(56)$ \\
\hline \multirow[t]{3}{*}{ miR-5118 } & Ngfr & Nerve growth factor receptor & $(54)$ \\
\hline & Sh3kbp1 & SH3-domain kinase binding protein 1 & $(57)$ \\
\hline & Ube $2 \mathrm{~d} 2 \mathrm{a}$ & Ubiquitin-conjugating enzyme E2D 2A & $(56)$ \\
\hline \multirow[t]{2}{*}{$\operatorname{miR}-449 a-5 p$} & Arhgap26 & Rho GTPase activating protein 26 & $(58)$ \\
\hline & Atp2b4 & ATPase $\mathrm{Ca}^{++}$transporting plasma membrane 4 & $(36)$ \\
\hline \multirow[t]{2}{*}{ miR-361-3p } & Rptor & Regulatory associated protein of MTOR complex 1 & $(59)$ \\
\hline & Map3k9 & Mitogen-activated protein kinase kinase kinase 9 & $(33,34)$ \\
\hline \multirow[t]{2}{*}{$\operatorname{miR}-322-3 p$} & Mett19 & Methyltransferase like 9 & $(60)$ \\
\hline & Ptpre & Protein tyrosine phosphatase receptor type E & $(37)$ \\
\hline \multirow[t]{2}{*}{$\operatorname{miR}-3103-3 p$} & Nfrkb & Nuclear factor related to $\kappa \mathrm{B}$ binding protein & $(35)$ \\
\hline & Arhgap 30 & Rho GTPase-activating protein 30 & $(58)$ \\
\hline \multirow[t]{2}{*}{$\operatorname{miR}-433-3 p$} & Creb1 & cAMP responsive element binding protein 1 & $(61)$ \\
\hline & Map2 & Microtubule-associated protein 2 & $(62)$ \\
\hline
\end{tabular}

Target genes related to osteogenic differentiation and bone metabolism are listed. miR, microRNA.

Table II. Differentially expressed miRNAs in both bone tissue and in osteocytes with the same expression level trend, as indicated by miRNA microarray and quantitative PCR.

\section{A, Upregulated}

\begin{tabular}{lc}
\hline miRNA & miRbase accession no \\
\hline miR-5118 & MIMAT0020626 \\
miR-433-3p & MIMAT0001420 \\
miR-190a-5p & MIMAT0000220 \\
miR-470-5p & MIMAT0002111
\end{tabular}

\section{B, Downregulated}

\begin{tabular}{ll}
\hline miRNA & miRbase accession no. \\
\hline miR-3082-5P & MIMAT0014872 \\
miR-6348 & MIMAT0025091 \\
miR-669-5P & MIMAT0017346 \\
miR-32-3p & MIMAT0017050
\end{tabular}

The osteocytes were stimulated with mechanical tensile strain $(2,500 \mu \varepsilon, 0.5 \mathrm{~Hz}, 8 \mathrm{~h})$. miRNA/miR, microRNA.

ALP and level of OCN in the bone tissues. ALP activity and OCN levels are important markers of osteogenic differentiation $(28,29)$, and these markers are related to the deposition and mineralization of bone matrix (30). The present results indicated that treadmill training promoted the maturation and differentiation of bone tissue and was beneficial for bone health, which was consistent with the results of dynamic load countering ovariectomy-induced osteoporosis in rats (31) and mechanical stretch increasing osteogenesis-related protein expression in the bones of ovariectomized rats (32).

Subsequently, nine of the numerous differentially expressed miRNAs identified in the screening by miRNA microarray were selected for verification via RT-qPCR analysis, and the target genes of the nine miRNAs related to osteogenic differentiation were predicted. As an example, one target gene of miR-316-3p, Map3k9, is a MAPK signaling molecule (33). MAPKs function to regulate the key transcriptional mediators of osteoblast differentiation, with ERK and p38 MAPKs phosphorylating runt-related transcription factor 2 , the master regulator of osteoblast differentiation. ERK also activates ribosomal S6 kinase 2, which in turn phosphorylates activating transcription factor 4 , a transcriptional regulator of late-stage osteoblast synthetic functions (34). One target gene of miR-3103-3p, nuclear factor related to $\mathrm{kB}$ binding protein, is related to the $\mathrm{NF}-\kappa \mathrm{B}$ signaling pathway (35). The transcription factor $N F-\kappa B$ is a member of a family of proteins involved in signaling pathways that are essential for normal cellular functions and development (35). Deletion of various components of this pathway results in abnormal skeletal development, research in the last decade has indicated that $\mathrm{NF}-\kappa \mathrm{B}$ signaling 
Table III. Predicted target genes of differentially expressed miRNAs both in bone tissue and osteocytes.

\begin{tabular}{lclc}
\hline miRNA & Target gene & \multicolumn{1}{c}{ Gene description } & $($ Refs.) \\
\hline miR-5118 & DKK2 & Dickkopf homolog 2 & $(63)$ \\
& Wnt2b & Wingless related MMTV integration site 2b & $(51)$ \\
& Fzd5 & Frizzled homolog 5 & $(64)$ \\
miR-433-3p & Tgfbr1 & Transforming growth factor $\beta$ receptor & $(40,41)$ \\
& Creb1 & cAMP responsive element binding protein 1 & $(61)$ \\
miR-190a-5p & Map2 & Microtubule-associated protein 2 & $(62)$ \\
miR-470-5p & Smad2 & SMAD family member 2 & $(39,47)$ \\
& DKK2 & Dickkopf homolog 2 & $(63)$ \\
& ATP2b1 & Plasma membrane calcium ATPase & $(59)$ \\
miR-3082-5p & Runx2 & Runt related transcription factor 2 & $(65)$ \\
& Gria4 & Glutamate receptor ionotropic AMPA4 & $(66,67)$ \\
miR-6348 & Creb1 & cAMP responsive element binding protein 1 & $(61)$ \\
& Map3k12 & Activated protein kinase kinase kinase 12 & $(33,34)$ \\
miR-669-5p & Dnm3 & Dynamin 3 & $(68)$ \\
& Creb1 & cAMP responsive element binding protein 1 & $(61)$ \\
miR-32-3p & Cask & Calcium/calmodulin-dependent serine protein kinase & $(69)$ \\
& Tgfbr1 & Transforming growth factor $\beta$ receptor & $(40,41)$ \\
& ATP13a3 & ATPase type 13A3 & $(70,71)$ \\
& Dnm3 & Dynamin 3 & $(68)$ \\
\hline
\end{tabular}

Target genes related to osteogenic differentiation and bone metabolism are listed. miRNA/miR, microRNA.

mediates RANK ligand-induced osteoclastogenesis (35). Plasma membrane $\mathrm{Ca}^{2+}$-transporting ATPase 4, a target gene of miR-449a-5p, has been proven to be overexpressed during the maturation or senescence of bone tissue cells (36). In addition, protein tyrosine phosphatase receptor type $\mathrm{E}$, a target gene of miR-322-3p, belongs to the protein tyrosine kinase family and overexpression of this kinase may promote osteogenic differentiation (37). These target genes and their signaling pathways have been confirmed to be related to osteogenic differentiation or bone metabolism.

In addition, the differentially expressed miRNAs in the bones of the exercised mice were compared with the differentially expressed miRNAs in mechanically strained osteocytes in vitro. A total of eight differentially expressed miRNAs in both bone tissues and osteocytes were identified, and each of these miRNAs had the same expression trend in bone tissues and osteocytes. Of these, four miRNAs (miR-5118, miR-433-3p, miR-190a-5p and miR-470-5p) were upregulated and four miRNAs (miR-3082-5p, miR-6438, miR-669-5p and miR-32-3p) were downregulated, and these results were confirmed via miRNA microarray and RT-qPCR. Furthermore, the target genes of the eight differentially expressed miRNAs were predicted and certain target genes were confirmed to be related to osteogenic differentiation or bone metabolism. For instance, Wnt2b, one of the target genes of miR-5118, is a molecule of the Wnt $\beta$-catenin signaling pathway and activation of $\mathrm{Wnt} / \beta$-catenin signaling may promote osteogenic differentiation and increase mechanically induced bone formation (38). Smad2, a target gene of miR-190a-5p, is a Smad signaling molecule and mechanical stress rapidly inhibits Smad3 phosphorylation, thereby inhibiting the activity of the key transforming growth factor- $\beta$ (TGF- $\beta$ ) effectors Smad 2 and Smad3 in osteocytes, and maintaining bone homeostasis via TGF- $\beta$ signaling (39). In the present study, downregulation of miR- $669 m-5 p$ expression was associated with one of its target genes, TGF- $\beta$ receptor 1 , and the reduction in TGF- $\beta$ signaling, through its effector SMAD3, enhanced the mechanical properties and mineral concentration of the bone matrix as well as the bone mass $(40,41)$.

The present results indicated that exercise-induced differentially expressed miRNAs in the bone most likely regulate bone metabolism and osteoblastic differentiation, and the same miRNAs that were differentially expressed in both mechanically stimulated osteocytes in vitro and in the bone tissues of mice subjected to exercise on a treadmill, also probably regulate bone metabolism and osteoblastic differentiation.

As terminally differentiated cells, osteocytes that are mechanically stimulated produce factors such as proteins, peptides and signaling molecules that regulate osteogenic differentiation or bone metabolism $(42,43)$. Mechanical stimuli, such as fluid shear stress, increase the number of exosomes released by osteocytes, these exosomes contain factors such as sclerotinins, $\mathrm{NF}-\kappa \mathrm{B}$ receptor activators and osteoprotegerin, which regulate osteogenic differentiation $(44,45)$. Certain osteocyte-derived miRNAs, such as miR-218, may influence osteoblastic differentiation (46). Therefore, in the present study, it was hypothesized that these differentially expressed miRNAs 
in mechanically stimulated osteocytes in vitro and in bone tissue of treadmill trained mice likely regulate osteogenic differentiation or bone metabolism. It is hypothesized that this regulatory mechanism may be via exosomes, thus in the future, how these miRNAs regulate osteogenic differentiation or bone metabolism through exosomes will be studied.

In conclusion, treadmill training resulted in the differential expression of miRNAs in the bone tissues of mice. Certain differentially expressed miRNAs were also observed in osteocytes and these miRNAs probably have an important role in the regulation of bone metabolism and osteogenic differentiation.

\section{Acknowledgements}

Not applicable.

\section{Funding}

The present study was supported by the National Nature Science Foundation of China (grant nos. 31660261 and 32071309) and the Natural Science Foundation of Guangxi (grant nos. 2018JIA140050 and 2018GXNSFAA281357).

\section{Availability of data and materials}

The datasets used and/or analyzed during the current study are available from the corresponding author on reasonable request. The datasets generated and/or analyzed during the current study are available in the Gene Expression Omnibus repository, [https://www.ncbi.nlm.nih. gov/geo/query/acc.cgi?acc=GSE179199 and https://www.ncbi. nlm.nih.gov/geo/query/acc.cgi?acc=GSE179201].

\section{Authors' contributions}

YG and JG designed the study, analyzed the data and participated in the bioinformatics analysis. HY and ZC performed all the RT-qPCR analyses at Guangzhou RiboBio Co., Ltd., (experimental equipment and reagents were provided by Guangzhou RiboBio Co., Ltd.)., and assays for ALP activity and OCN levels, and participated in the animal experiments. YW and JW performed the miRNA microarray at Guangzhou RiboBio Co., Ltd., (experimental equipment and reagents were provided by Guangzhou RiboBio Co., Ltd.), and performed the animal experiments. BH, FY and YQ performed the bioinformatics analysis and detected the mechanical properties of the mouse femur bones. YG, HY and ZC wrote and revised the manuscript. All authors have read and approved the final manuscript. YG, JG, HY, ZC, YW, JW, BH, FY and YQ confirm the authenticity of all the raw data.

\section{Ethics approval and consent to participate}

The present study involved animals and was approved by the Animal Ethics Committee of Guilin Medical University (Guilin, China; approval no. 2019-0013). All of the authors declare that the experiments complied with the current laws of China (Guangxi) where they were performed.

\section{Patient consent for publication}

Not applicable.

\section{Competing interests}

The authors declare that they have no competing interests.

\section{References}

1. Belavý DL, Baecker N, Armbrecht G, Beller G, Buehlmeier J, Frings-Meuthen P, Rittweger J, Roth HJ, Heer M and Felsenberg D: Serum sclerostin and DKK 1 in relation to exercise against bone loss in experimental bed rest. Bone Miner Metab 34: 354-365, 2016.

2. Zhao JG, Zeng XT, Wang J and Liu L: Association between calcium or vitamin D supplementation and fracture incidence in community-dwelling older adults: A systematic review and meta analysis. JAMA 318: 2466-2482, 2017.

3. Yamazaki S, Ichimura S, Iwamoto J, Takeda T and Toyama Y: Effect of walking exercise on bone metabolism in postmenopausal women with osteopenia/osteoporosis. Bone Miner Metab 22: 500-508, 2004.

4. Wen HJ, Huang TH, Li TL, Chong PN and Ang BS: Effects of short-term step aerobics exercise on bone metabolism and functional fitness in postmenopausal women with low bone mass. Osteoporos Int 28: 539-547, 2017.

5. Vainionpää A, Korpelainen R, Väänänen HK, Haapalahti J, Jämsä T and Leppäluoto J: Effect of impact exercise on bone metabolism. Osteoporos Int 20: 1725-1733, 2009.

6. Weaver CM, Gordon CM, Janz KF, Kalkwarf HJ, Lappe JM, Lewis R, O'Karma M, Wallace TC and Zemel BS: The national osteoporosis foundation's position statement on peak bone mass development and lifestyle factors: A systematic review and implementation recommendations. Osteoporos Int 27: 1281-1386, 2016.

7. Polidoulis I, Beyene J and Cheung AM: The effect of exercise on pQCT parameters of bone structure and strength in postmenopausal women-a systematic review and meta-analysis of randomized controlled trials. Osteoporos Int 23: 39-51, 2012.

8. Iwamoto J, Yeh JK and Aloia JF: Differential effect of treadmill exercise on three cancellous bone sites in the young growing rat. Bone 24: 163-169, 1999.

9. Ma T, Li SC, Liang XX, Luo J and Li ZX: Effects of uphill or downhill running on bone mineral density and the indexes of bone histomorphometry in ovariectomized mice. Sports Sci 31: 48-55, 2011. (In Chinese).

10. Ma T and Li SC: Effect of uphill or downhill running on the osteoclast differentiation of ovariectomized mice. Chin J Sports Med 34: 468-474, 2015 (In Chinese)

11. Borer KT, Zheng Q, Jafari A, Javadi S and Kernozek T: Nutrient intake prior to exercise is necessary for increased osteogenic marker response in diabetic postmenopausal women. Nutrients 11: 1494, 2019.

12. Zhai Y, Tyagi SC and Tyagi N: Cross-talk of microRNA and hydrogen sulfide: A novel therapeutic approach for bone diseases. Biomed Pharmacother 92: 1073-1084, 2017.

13. Lanyon LE: Control of bone architecture by functional load bearing. Bone Miner Res 7 (Suppl 2): S369-S375, 1992.

14. Yuan Y, Guo J, Zhang L, Tong X, Zhang S, Zhou X, Zhang M, Chen X, Lei L, Li H, et al: miR-214 attenuates the osteogenic effects of mechanical loading on osteoblasts. Int J Sports Med 40: 931-940, 2019.

15. Wang H, Sun Z, Wang Y, Hu Z, Zhou H, Zhang L, Hong B, Zhang S and Cao X: MiR-33-5p, a novel mechano-sensitive microRNA promotes osteoblast differentiation by targeting Hmga2. Sci Rep 6: 23170, 2016.

16. Iwawaki Y, Mizusawa N, Iwata T, Higaki N, Goto T, Watanabe M, Tomotake Y, Ichikawa T and Yoshimoto K: miR-494-3p induced by compressive force inhibits cell proliferation in MC3T3-E1 cells. J Biosci Bioeng 120: 456-462, 2015.

17. Chen N, Sui BD, Hu CH, Cao J, Zheng CX, Hou R, Yang ZK, Zhao P, Chen Q, Yang QJ, et al: MicroRNA-21 contributes to orthodontic tooth movement. J Dent Res 95: 1425-1433, 2016.

18. Wang Y, Jia L, Zheng Y and Li W: Bone remodeling induced by mechanical forces is regulated by miRNAs. Biosci Rep 38: BSR20180448, 2018. 
19. Wang Y, Wang K, Hu Z, Zhou H, Zhang L, Wang H, Li G, Zhang S, Cao X and Shi F: MicroRNA-139-3p regulates osteoblast differentiation and apoptosis by targeting ELK1 and interacting with long noncoding RNA ODSM. Cell Death Dis 9: 1107, 2018.

20. Schaffler MB, Cheung WY, Majeska R and Kennedy O: Osteocytes: Master orchestrators of bone. Calcif Tissue Int 94: $5-24,2013$

21. Zeng QC, Wang Y, Gao J, Yan ZX, Li ZH, Zou XQ, Li YN, Wang JH and Guo Y: miR-29b-3p regulated osteoblast differentiation via regulating IGF-1 secretion of mechanically stimulated osteocytes. BioMed Central 24: 11, 2019.

22. Mosley JR: Osteoporosis and bone functional adaptation: Mechanobiological regulation of bone architecture in growing and adult bone, a review. J Rehabil Res Dev 37: 189-199, 2000.

23. Rubin CT and Lanyon LE: Regulation of bone formation by applied dynamic loads. Bone Joint Surg Am 66: 397-402, 1984.

24. Hillam RA and Skerry TM: Inhibition of bone resorption and stimulation of formation by mechanical loading of the modeling rat ulna in vivo. J Bone Miner Res 5: 683-689, 1995.

25. Yoshiya S: The effects of exercise and sports activities on bone and joint morbidities. Clin Calcium 27: 39-43, 2017 (In Japanese).

26. Singh MA: Physical activity and bone health. Aust Fam Physician 33: 125, 2004.

27. Santos L, Elliott-Sale KJ and Sale C: Exercise and bone health across the lifespan. Biogerontology 18: 931-946, 2017.

28. Jang WG, Koh JT and Kim EJ: Tunicamycin negatively regulates BMP2-induced osteoblast differentiation through CREBH expression in MC3T3E1 cells. BMB Rep 44: 735-740, 2011.

29. Beck GJ Jr, Zerler B and Moran E: Phosphate is a specific signal for induction of osteopontin gene expression. Proc Natl Acad Sci USA 97: 8352-8357, 2000.

30. Mahalingam CD, Datta T, Patil RV, Kreider J, Bonfil RD, Kirkwood KL, Goldstein SA, Abou-Samra AB and Datta NS: Mitogen-activated protein kinase phosphatase 1 regulates bone mass, osteoblast gene expression, and responsiveness to parathyroid hormone. J Endocrinol 211: 145-156, 2011.

31. Li H, Li RX, Wan ZM, Xu C, Li JY, Hao QX, Guo Y, Liu L and Zhang XZ: Counter-effect of constrained dynamic loading on osteoporosis in ovariectomized mice. J Biomech 46: 1242-1247, 2013.

32. Wu Y, Zhang P, Dai Q, Yang X, Fu R, Jiang L and Fang B: Effect of mechanical stretch on the proliferation and differentiation of BMSCs from ovariectomized rats. Mol Cell Biochem 382: 273-282, 2013

33. Cong Q, Jia H, Li P, Qiu S, Yeh J, Wang Y, Zhang ZL, Ao J, $\mathrm{Li} \mathrm{B}$ and Liu H: P38 $\alpha$ MAPK regulates proliferation and differentiation of osteoclast progenitors and bone remodeling in an aging-dependent manner. Sci Rep 7: 45964, 2017.

34. Greenblatt MB, Shim JH and Glimcher LH: Mitogen-activated protein kinase pathways in osteoblasts. Annu Rev Cell Dev Biol 29: 63-79, 2013.

35. Abu-Amer $\mathrm{Y}$ : NF- $\mathrm{kB}$ signaling and bone resorption. Osteoporos Int 24: 2377-2386, 2013.

36. Yoo JK, Choi SJ and Kim JK: Expression profiles of subtracted mRNAs during cellular senescence in human mesenchymal stem cells derived from bone marrow. Exp Gerontol 5: 464-471, 2013.

37. Wang H, Ye X, Xiao H, Zhu N, Wei C, Sun X, Wang L, Wang B, Yu X, Lai X, et al: PTPN21 overexpression promotes osteogenic and adipogenic differentiation of bone marrow-derived mesenchymal stem cells but inhibits the immunosuppressive function. Stem Cells Int 2019: 4686132, 2019.

38. Liedert A, Nemitz C, Haffner-Luntzer M, Schick F, Jakob F and Ignatius A: Effects of estrogen receptor and Wnt signaling activation on mechanically induced bone formation in a mouse model of postmenopausal bone loss. Int J Mol Sci 21: 8301, 2020.

39. Nguyen J, Tang SY, Nguyen D and Alliston T: Load regulates bone formation and Sclerostin expression through a TGF $\beta$-dependent mechanism. PLoS One 8: e53813, 2013.

40. Zhang H, Huang W, Liu H, Zheng Y and Liao L: Mechanical stretching of pulmonary vein stimulates matrix metalloproteinase- 9 and transforming growth factor- $\beta 1$ through stretch-activated channel/MAPK pathways in pulmonary hypertension due to left heart disease model rats. PLoS One 15 e0235824, 2020

41. Balooch G, Balooch M, Nalla RK, Schilling S, Filvaroff EH, Marshall GW, Marshall SJ, Ritchie RO, Derynck R and Alliston T: TGF-beta regulates the mechanical properties and composition of bone matrix. Proc Natl Acad Sci USA 102: 18813-18818, 2005.
42. Klein-Nulend J, Bakker AD, Bacabac RG, Vatsa A and Weinbaum S: Mechanosensation and transduction in osteocytes. Bone 54: 182-190, 2013.

43. Yan Y, Wang L, Ge L and Pathak JL: Osteocyte-mediated translation of mechanical stimuli to cellular signaling and its role in bone and non-bone-related clinical complications. Curr Osteoporos Rep 18: 67-80, 2020.

44. Morrell AE, Brown GN, Robinson ST, Sattler RL, Baik AD, Zhen G, Cao X, Bonewald LF, Jin W, Kam LC and Guo XE: Mechanically induced $\mathrm{Ca}^{2+}$ oscillations in osteocytes release extracellular vesicles and enhance bone formation. Bone Res 6: 6, 2018

45. Eichholz KF, Woods I, Riffault M, Johnson GP, Corrigan M, Lowry MC, Shen N, Labour MN, Wynne K, O'Driscoll L and Hoey DA: Human bone marrow mesenchymal stem/stromal cell behaviour is coordinated via mechanically activated osteocyte-derived extracellular vesicles. Stem Cells Transl Med 9: 1431-1447, 2020.

46. Qin Y, Peng Y, Zhao W, Pan J, Ksiezak-Reding H, Cardozo C, Wu Y, Divieti PP, Bonewald LF, Bauman WA and Qin W: Myostatin inhibits osteoblastic differentiation by suppressing osteocyte-derived exosomal microRNA-218: A novel mechanism in muscle-bone communication. J Biol Chem 292: 11021-11033, 2017.

47. Zheng W, Chen Q, Zhang Y, Xia R, Gu X, Hao Y, Yu Z, Sun X and Hu D: BMP9 promotes osteogenic differentiation of SMSCs by activating the JNK/Smad2/3 signaling pathway. J Cell Biochem 121: 2851-2863, 2020.

48. Walker LM, Publicover SJ, Preston MR, Said Ahmed MA and El Haj AJ: Calcium-channel activation and matrix protein upregulation in bone cells in response to mechanical strain. J Cell Biochem 79: 648-661, 2000.

49. Uda Y, Azab E, Sun N, Shi C and Pajevic PD: Osteocyte mechanobiology. Curr Osteoporos Rep 15: 318-325, 2017.

50. Mazur CM, Woo JJ, Yee CS, Fields AJ, Acevedo C, Bailey KN, Kaya S, Fowler TW, Lotz JC, Dang A, et al: Osteocyte dysfunction promotes osteoarthritis through MMP13-dependent suppression of subchondral bone homeostasis. Bone Res 7: 34, 2019.

51. Lerner UH and Ohlsson C: The WNT system: Background and its role in bone. J Intern Med 277: 630-649, 2015.

52. Chen Y, Mohammed A, Oubaidin M, Evans CA, Zhou X, Luan X, Diekwisch TG, Atsawasuwan P: Cyclic stretch and compression forces alter microRNA-29 expression of human periodontal ligament cells. Gene 566: 13-17, 2015.

53. Pozio A, Palmieri A, Girardi A, Cura F and Carinci F: Titanium nanotubes activate genes related to bone formation in vitro. Dent Res J (Isfahan) 9 (Suppl 2): S164-S168, 2012.

54. Yasui M, Shiraishi Y, Ozaki N, Hayashi K, Hori K, Ichiyanagi M and Sugiura Y: Nerve growth factor and associated nerve sprouting contribute to local mechanical hyperalgesia in a rat model of bone injury. Eur J Pain 16: 953-965, 2012.

55. Shi J, Wang Z, Guo X, Shen J, Sun H, Bai J, Yu B, Wang L, Zhou W, Liu Y, et al: Spirin inhibits osteoclast formation and wear-debris-induced bone destruction by suppressing mitogen-activated protein kinases. J Cell Physiol 235: 599-2608, 2020 .

56. Vriend $\mathrm{J}$ and Reiter RJ: Melatonin, bone regulation and the ubiquitin-proteasome connection: A review. Life Sci 145: 152-160, 2016.

57. Matsumoto $\mathrm{Y}$ and Rottapel R: Bone dynamics and inflammation: Lessons from rare diseases. Immunol Med 43: 61-64, 2020.

58. Hamamura K, Swarnkar G, Tanjung N, Cho E, Li J, Na S and Yokota H: RhoA-mediated signaling in mechanotransduction of osteoblasts. Connect Tissue Res 53: 398-406, 2012.

59. Rosselli-Murai LK, Almeida LO, Zagni C, Galindo-Moreno P, Padial-Molina M, Volk SL, Murai MJ, Rios HF, Squarize CH and Castilho RM: Periostin responds to mechanical stress and tension by activating the MTOR signaling pathway. PLoS One 8: e83580, 2013

60. Lorentzon M, Eriksson AL, Nilsson S, Mellström D and Ohlsson C: Association between physical activity and BMD in young men is modulated by catechol-O-methyltransferase (COMT) genotype: The GOOD study. J Bone Miner Res 22: 1165-1172, 2007.

61. Chen B, Lin T, Yang X, Li Y, Xie D and Cui H: Intermittent parathyroid hormone (1-34) application regulates cAMP-response element binding protein activity to promote the proliferation and osteogenic differentiation of bone mesenchymal stromal cells, via the cAMP/PKA signaling pathway. Exp Ther Med 11: 2399-2406, 2016. 
62. Yin C, Zhang Y, Hu L, Tian Y, Chen Z, Li D, Zhao F, Su P, Ma X, Zhang G, et al: Mechanical unloading reduces microtubule actin crosslinking factor 1 expression to inhibit $\beta$-catenin signaling and osteoblast proliferation. J Cell Physiol 233: 5405-5419, 2018.

63. Olivares-Navarrete R, Hyzy S, Wieland M, Boyan BD and Schwartz Z: The roles of Wnt signaling modulators Dickkopf-1 (Dkk1) and Dickkopf-2 (Dkk2) and cell maturation state in osteogenesis on microstructured titanium surfaces. Biomaterials 313: 2015-2024, 2010.

64. Leijten JC, Bos SD, Landman EB, Georgi N, Jahr H, Meulenbelt I, Post JN, van Blitterswijk CA and Karperien M: GREM1, FRZB and DKK1 mRNA levels correlate with osteoarthritis and are regulated by osteoarthritis-associated factors. Arthritis Res Ther 15: R126, 2013.

65. Galea GL,Paradise CR,MeakinLB,CamilleriET, TaipaleenmakiH, Stein GS, Lanyon LE, Price JS, van Wijnen AJ and Dudakovic A: Mechanical strain-mediated reduction in RANKL expression is associated with RUNX2 and BRD2. Gene X 5: 100027, 2020.

66. Szczesniak AM, Gilbert RW, Mukhida M and Anderson GI Mechanical loading modulates glutamate receptor subunit expression in bone. Bone 37: 63-73, 2005.

67. Lin TH, Yang RS, Tang CH, Wu MY and Fu WM: Regulation of the maturation of osteoblasts and osteoclastogenesis by glutamate. Eur J Pharmacol 589: 37-44, 2008.
68. Eleniste PP, Huang S, Wayakanon K, Largura HW and Bruzzaniti A: Osteoblast differentiation and migration are regulated by dynamin GTPase activity. Int J Biochem Cell Biol 46: 9-18, 2014.

69. Naghii MR, Torkaman G and Mofid M: Effects of boron and calcium supplementation on mechanical properties of bone in rats. Biofactors 28: 195-201, 2006.

70. Nakano Y, Forsprecher J and Kaartinen MT: Regulation of ATPase activity of transglutaminase 2 by MT1-MMP: Implications for mineralization of MC3T3-E1 osteoblast cultures. Cell Physiol 223: 260-269, 2010.

71. Sun D, Junger WG, Yuan C, Zang W, Bao Y, Qin D, Wang C, Tan L, Qi B, Zhu D, et al: Shockwaves induce osteogenic differentiation of human mesenchymal stem cells through ATP release and activation of $\mathrm{P} 2 \mathrm{X} 7$ receptors. Stem Cells 31: 1170-1180, 2013.

This work is licensed under a Creative Commons Attribution-NonCommercial-NoDerivatives 4.0 International (CC BY-NC-ND 4.0) License. 